\title{
Clinical Parameters and CRP Levels in Generalized Aggressive Periodontitis Patient: A Case Report
}

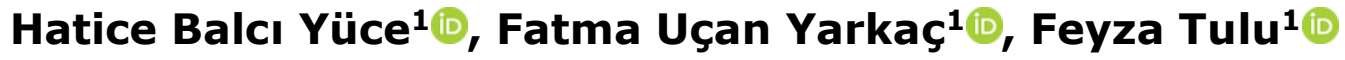 \\ ${ }^{1}$ Gaziosmanpasa University, Faculty of Dentistry, Department of Periodontology, Tokat, Turkey.
}

\section{Correspondence:}

Dr. Fatma UÇAN YARKAÇ

Gaziosmanpasa University, Faculty of

Dentistry, Department of

Periodontology, Tokat, TURKEY.

E-mail:fatma_ucan413@hotmail.com

Received: 16 January 2018

Accepted: 11 February 2018

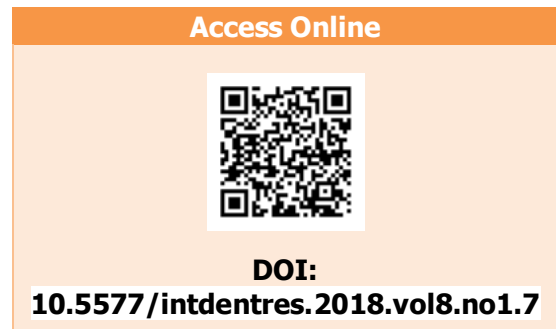

\section{Introduction}

Periodontal disease is a chronic inflammatory and infectious disease of the periodontium primarily caused by dental plaque. There are two forms of the disease, namely chronic periodontitis (CP) and aggressive periodontitis (AGP) (1). In both forms, bacterial protein

\begin{abstract}
Aim: Generalised aggressive periodontitis (G-AGP) is the most severe and destructive form of periodontitis. It usually starts at the age of 30 years, and it is difficult to recover tissue health through periodontal treatment alone. This investigation was conducted to evaluate the effect of full-mouth ozone treatment on clinical parameters and blood C-reactive protein (CRP) levels in a patient with G-AGP.

Methodology: A 23-year-old male patient was diagnosed with GAGP. Clinical attachment level (CAL), plaque index ( $\mathrm{PI})$, gingival index $(\mathrm{Gl})$, bleeding on probing (BoP) and blood CRP levels were recorded. Full-mouth scaling and root planing and ozone application were performed.

Results: Baseline mean full-mouth PI, GI scores and CAL were 3.0, 2.0 and $5.2 \mathrm{~mm}$, respectively. About $42 \%$ of the sites showed a CAL of 4-6 $\mathrm{mm}$, while $26 \%$ of the sites showed a CAL of $\geq 7 \mathrm{~mm}$. BoP was detected in $72 \%$ of the sites. Fifteen teeth had a CAL of $\geq 6 \mathrm{~mm}$. After treatment, both the PI and the GI scores were 1.0, the CAL was 4-6 $\mathrm{mm}$ in $19 \%$ of the sites and $\geq 7 \mathrm{~mm}$ in $16 \%$ of the sites and BoP was observed in $12 \%$ of the sites. Six teeth had a CAL of $\geq 6 \mathrm{~mm}$. Baseline CRP level was $9 \mathrm{mg} / \mathrm{L}$ and increased to $34 \mathrm{mg} / \mathrm{L}$ during the treatment and then decreased to $2 \mathrm{mg} / \mathrm{L}$ after 4 weeks.

Conclusions: Within the limitations of this case report, it could be suggested that monitoring CRP levels and subgingival ozone application might be beneficial in treating G-AGP.
\end{abstract}

Keywords: Aggressive periodontitis, ozone therapy, C-reactive

How to cite this article: Balcı Yüce H, Uçan Yarkaç F, Tulu F. Clinical Parameters and CRP Levels in Generalized Aggressive Periodontitis Patient: Case Report. Int Dent Res 2018;8(1):39-44. accumulation initiates an inflammatory process and host-bacterial interactions determine the disease course. In AGP, a bacterial component of dental plaque and the response to these bacteria are different from $\mathrm{CP}$, resulting in a slower disease course (1). The treatment protocols of these diseases are also different. CP generally responds well to conventional 
periodontal treatment, whereas AGP requires additional applications such as antibacterial agents (2). AGP has two clinical classifications; one is a localised form and the other is a generalised form, both of which have similar characteristics such as a noncontributing medical history, severe destruction and involvement of Aggregatibacter actinomycetemcomitans (A.a) (3). However, generalised AGP (G-AGP) causes more rapid attachment loss, bone destruction and tooth loss. GAGP usually affects people below the age of 30 years and differs from localised AGP (L-AGP) according to the familial disease history and the number of affected teeth (4). L-AGP primarily affects the central incisors and the first molars, whereas G-AGP affects at least six other teeth other than the central incisors and the first molars. Although the treatment protocols of L-AGP and G-AGP are similar, the prognosis of G-AGP is poorer than L-AGP (5).

The most important goal of treatment of AGP is to eliminate or reduce subgingival microorganisms, regenerate lost tissues and preserve periodontal health $(6-8)$. Non-surgical periodontal treatment is considered to be the gold standard for the maintenance of periodontal health by the elimination of bacterial plaque. However, non-surgical treatment alone cannot eliminate all periodontopathogens and improve periodontal health in G-AGP (9). To increase treatment success, several applications (chlorhexidine, ozonized water, polyvinylpyrrolidone iodine complex etc.) such as a subgingival application of gaseous ozone and irrigation with antiseptics have been recommended in the literature $(10,11)$.

Ozone is a gaseous mixture consisting of $0.05 \%-5 \%$ pure ozone and $95 \%-99.95 \%$ oxygen, which is applied to achieve medical goals. Application of ozone has some advantages such as disinfection, antibacterial efficacy and improvement of periodontal wound healing $(12,13)$. Early diagnosis of G-AGP might help in preventing the disease development and/or in taking precautions. As G-AGP is an inflammatory disease, detecting systemic and/or local infection and inflammatory markers might be beneficial in the early diagnosis. C-reactive protein (CRP) is the most common marker of infection that is produced in reaction to numerous forms of injuries such as periodontitis, diabetes, trauma, cardiovascular diseases and other infections $(14,15)$. Therefore, the aim of the present study was to evaluate the efficacy of CRP as a diagnostic marker and the effect of subgingival ozone application on periodontal healing in a patient with $\mathrm{G}$ AGP.

\section{Materials and Methods}

A 23-year-old systemically healthy male patient with complaints of gingival bleeding, gingival recession, tooth sensitivity and tooth mobility was referred to Gaziosmanpasa University Faculty of Dentistry. Medical history and oral and radiographic examinations revealed severe periodontal destruction in all teeth (Fig. 1).

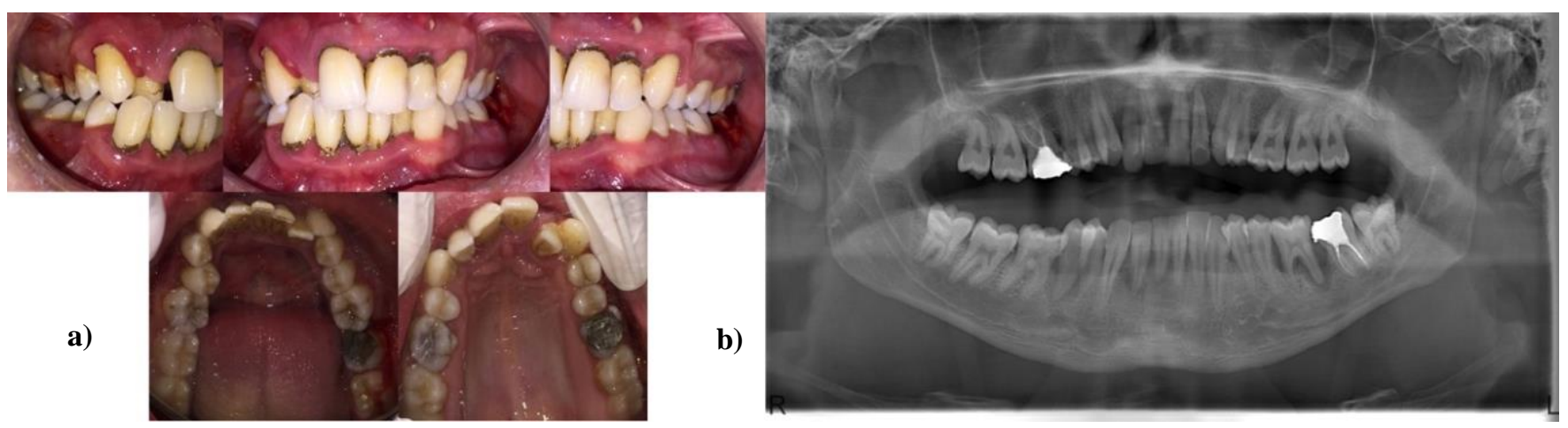

Figure 1. a) Clinical photographs, b) radiographical view of the case (baseline)

Full-mouth plaque index (PI) (16), gingival index (GI) (17), amount of gingival recession, bleeding on probing (BoP), clinical attachment level (CAL) and the number of teeth existing in the mouth were recorded. CAL was determined at six measurement sites of each tooth (mesiobuccal, buccal, distobuccal, mesiopalatal, palatal and distopalatal). The presence or absence of BoP was recorded per tooth, and the percentage of BoP was calculated by dividing the number of bleeding sites by the number of teeth (18). All periodontal measurements were performed using a Williams probe. At baseline, scaling and root planing (SRP) procedures were performed using ultrasonic instruments and Gracey curettes. Proper oral hygiene instructions were given, and ozone application was additionally performed a week after root planning.

A gaseous ozone generator was used for full-mouth ozone application (Ozonytron, MIO international Ozonytron GmbH, München, Germany) (Fig. 2). Ozone was applied individually for every single pocket in the periodontitis mode, which provides maximum access to deep pockets. The application was performed according to the manufacturer's instructions $(35 \mu \mathrm{g}$, 80sn PA/GI with periodontitis mode). 


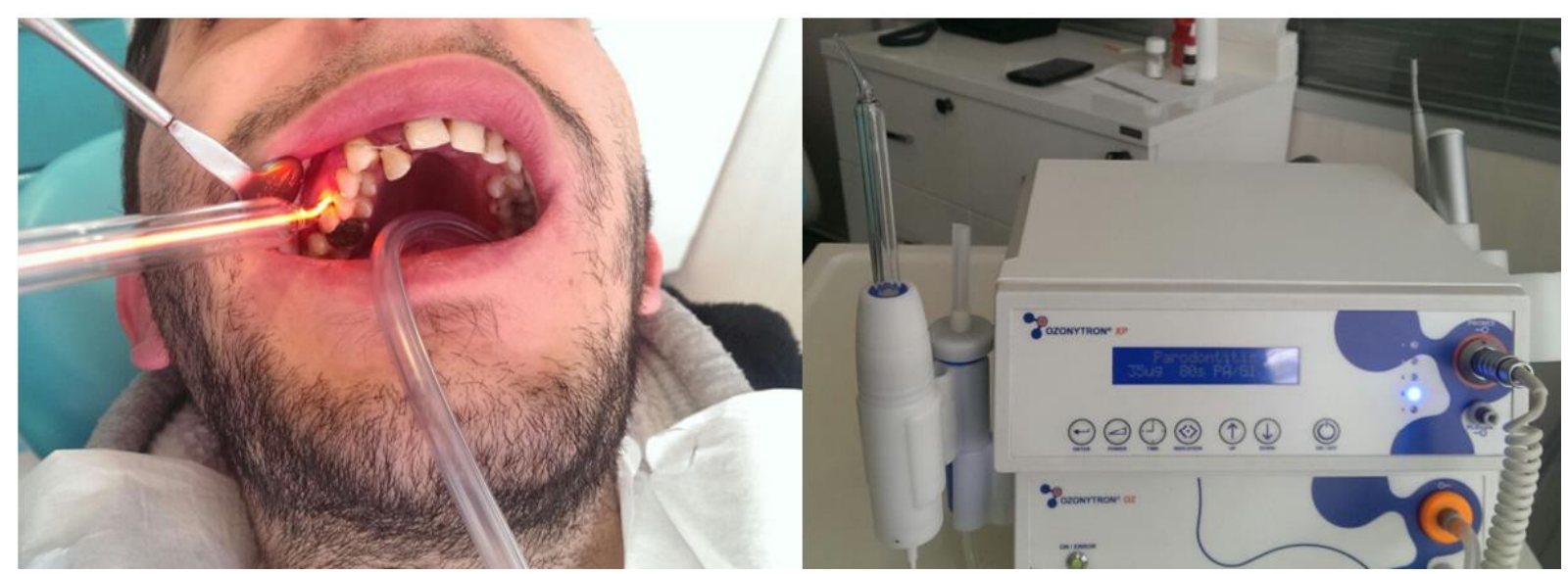

Figure 2. Full-mouth ozone application (Ozonytron, MIO international Ozonytron GmbH, München, Germany)

Venous blood samples, a total of six serum samples, were obtained as follows: at the first visit before the periodontal treatment, 1 day after scaling and root planning, 1 week after scaling and root planning, on the day of ozone application, 1 day after ozone application and 6 weeks after the initial periodontal treatment. The CRP levels in blood were determined by immunonephelometry with anti-CRP monoclonal antibodies, which allowed quantitative results (in milligrams per liter).

\section{Results}

Intraoral examination of the patient revealed severe attachment losses, pus formations and inflammation. After non-surgical periodontal therapy and ozone application, the periodontal status improved. Table 1 presents the results at the baseline and at the sixth week.

Mean full-mouth PI score was 3.0 at baseline and 1.0 after initial periodontal treatment. The patient was extremely motivated, and the plaque percentage levels were below $25 \%$. Mean full-mouth GI score was 2.0 at baseline and 1.0 at the sixth week. Before treatment, $72 \%$ of the sites exhibited BoP, which decreased to $12 \%$ after treatment.

The mean full-mouth CAL was $5.2 \mathrm{~mm}$. About $42 \%$ of the sites showed a CAL of $4-6 \mathrm{~mm}$, while $26 \%$ of the sites showed a CAL of $>7 \mathrm{~mm}$. Fifteen teeth showed a CAL of $\geq 6 \mathrm{~mm}$. After treatment, the mean full-mouth CAL was $2.075 \pm 1.86 \mathrm{~mm}$ in the maxilla and $1.67 \pm 1.4$ $\mathrm{mm}$ in the mandible; $19 \%$ of the sites showed a CAL of 4-6 $\mathrm{mm}$, and $16 \%$ of the sites showed a CAL of $\geq 7 \mathrm{~mm}$; six teeth had a CAL of $\geq 6 \mathrm{~mm}$ (Table 1).

Table 1. Baseline and post-treatment buccal (B)-lingual (L) clinical attachment levels (CAL)

\begin{tabular}{|l|c|c|c|c|c|c|c|c|c|c|c|c|c|c|}
\multicolumn{10}{c|}{ Baseline /Tooth mesial-midbuccal-distal measurement } \\
\hline Maxilla & 17 & 16 & 15 & 14 & 13 & 12 & 11 & 21 & 22 & 23 & 24 & 25 & 26 & 27 \\
\hline CAL(B)mm & 527 & 833 & 755 & 535 & 448 & 101114 & 538 & 557 & 10129 & 534 & 425 & 523 & 335 \\
\hline CAL(L)mm & 536 & 527 & 724 & 323 & 359 & 1278 & 577 & 7912 & 589 & 523 & 225 & 524 & 435 \\
\hline Mandible & 47 & 46 & 45 & 44 & 43 & 42 & 41 & 31 & 32 & 33 & 34 & 35 & 36 & 37 \\
\hline CAL(B)mm & 424 & 323 & 51011 & 734 & 435 & 834 & 977 & 753 & 444 & 425 & 724 & 324 & 91010 & 523 \\
\hline CAL(L)mm & 534 & 544 & 4910 & 535 & 335 & 6710 & 753 & 335 & 525 & 555 & 534 & 323 & 767 & 535 \\
\hline
\end{tabular}

Post-treatment /Tooth mesial-midbuccal-distal measurement

\begin{tabular}{|l|c|c|c|c|c|c|c|c|c|c|c|c|c|c|}
\hline Maxilla & $\mathbf{1 7}$ & $\mathbf{1 6}$ & $\mathbf{1 5}$ & $\mathbf{1 4}$ & $\mathbf{1 3}$ & $\mathbf{1 2}$ & $\mathbf{1 1}$ & $\mathbf{2 1}$ & $\mathbf{2 2}$ & $\mathbf{2 3}$ & $\mathbf{2 4}$ & $\mathbf{2 5}$ & $\mathbf{2 6}$ & $\mathbf{2 7}$ \\
\hline CAL(B)mm & 322 & 313 & 322 & 133 & 214 & 5108 & 523 & 535 & 564 & 333 & 322 & & 322 & 323 \\
\hline CAL(L)mm & 223 & 325 & 223 & 322 & 257 & 737 & 523 & 555 & 543 & 222 & 222 & & 323 & 323 \\
\hline Mandible & $\mathbf{4 7}$ & $\mathbf{4 6}$ & $\mathbf{4 5}$ & $\mathbf{4 4}$ & $\mathbf{4 3}$ & $\mathbf{4 2}$ & $\mathbf{4 1}$ & $\mathbf{3 1}$ & $\mathbf{3 2}$ & $\mathbf{3 3}$ & $\mathbf{3 4}$ & $\mathbf{3 5}$ & $\mathbf{3 6}$ & $\mathbf{3 7}$ \\
\hline CAL(B)mm & 323 & 322 & 499 & 322 & 213 & 322 & 334 & 432 & 222 & 222 & 612 & 223 & $\mathbf{7 7 6}$ & 323 \\
\hline CAL(L)mm & 332 & 323 & 475 & 322 & 223 & 334 & 453 & 112 & 222 & 354 & 534 & 312 & 755 & 333 \\
\hline
\end{tabular}


In general, CRP levels range from 0 to $5 \mathrm{mg} / \mathrm{L}$ in healthy people, whereas the CRP level of our patient was $8.8 \mathrm{mg} / \mathrm{L}$ at baseline. This level increased to 16.9 $\mathrm{mg} / \mathrm{L}$ on the first day after supragingival scaling but decreased to $7 \mathrm{mg} / \mathrm{L}$ after 1 week, which was the day before subgingival scaling and root planning. One day after subgingival treatment, the CRP level again increased to $32.4 \mathrm{mg} / \mathrm{L}$, and after full-mouth ozone application, it again increased to $34.5 \mathrm{mg} / \mathrm{L}$. During the follow-up period of 6 weeks, this level decreased to the normally accepted value ( $2 \mathrm{mg} / \mathrm{L}$ ) (Fig. 3 ).
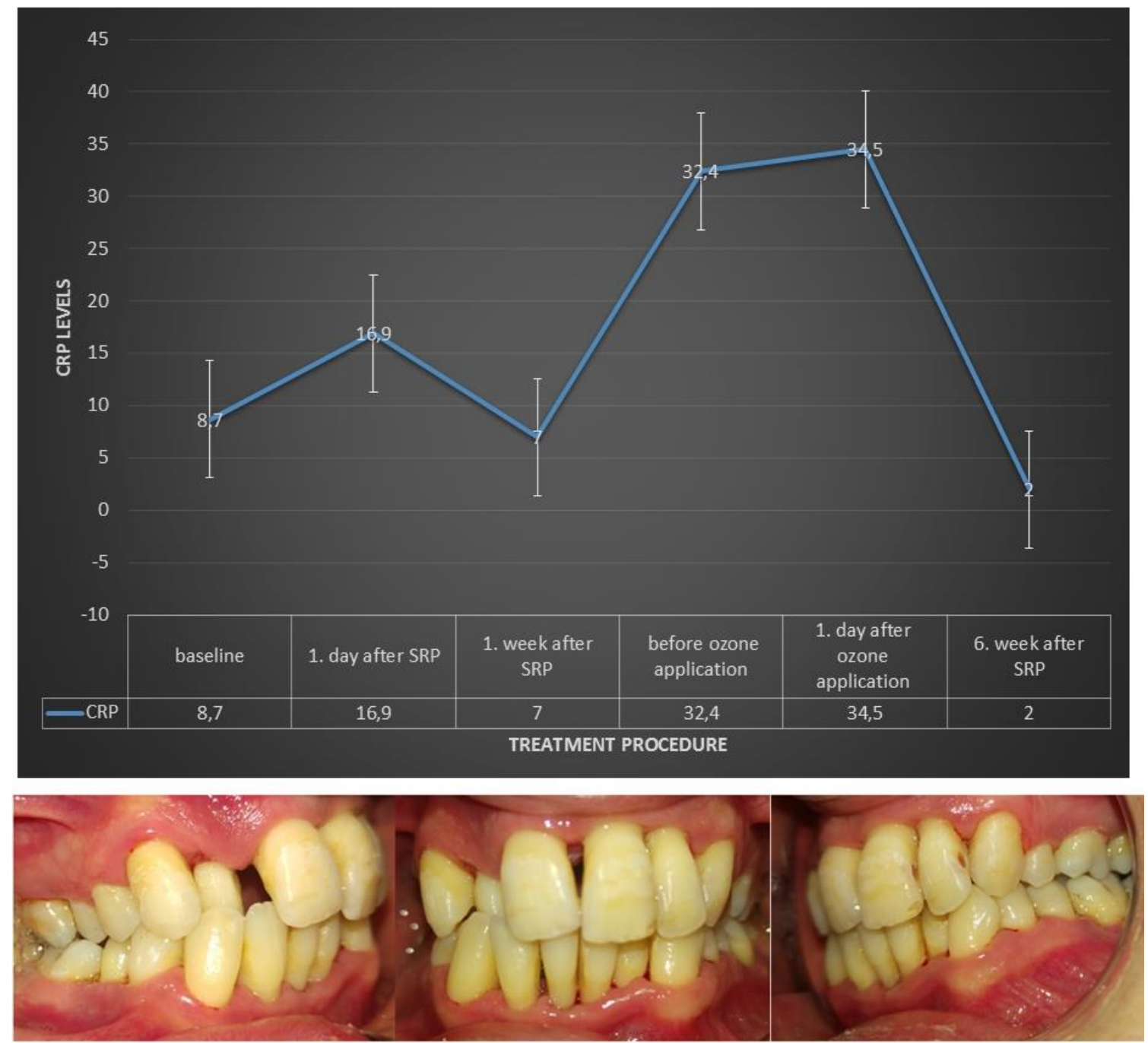

Figure 3. a) C-reactive protein levels in treatment procedure, b) Clinical photographs of the case (post-treatment)

\section{Discussion}

The treatment of AGP is a real challenge for clinicians. There are no established protocols and guidelines for an effective and complete treatment of the disease (5). The most accepted treatment measures consist of conventional mechanical nonsurgical and surgical treatments with diverse adjunctive anti-infective therapies such as antibacterial irrigation agents and antibiotics (19). As Aggregatibacter actinomycetemcomitans could invade gingival tissues and is generally related to AGP lesions, systemic and/or local antibiotics are usually recommended along with conventional treatment. (19).

There are certain disadvantages of chemotherapeutic therapy, which include bacterial resistance, adverse systemic effects of systemic antibiotics, cost of local antibacterial agents and alteration in regular oral microbial components (20). Ozone application that does not cause side effects might help overcome the disadvantages of chemotherapeutic therapy. The use of periodontal ozone treatment as an alternative to standard disinfectants and antiseptics has gained popularity in recent years (11). Seidler et al. demonstrated that ozone improved the periodontal status of patients with gingival and periodontal abscesses. In addition to improving abscesses, ozone improved the gingival health in patients with gingivitis (21). Ozone was also shown to be effective as an irrigation agent compared with chlorhexidine in patients with CP (11).

In the context of AGP, Ramzy et al. reported that ozone significantly decreased the PI, GI, CAL and bacterial counts (10). In the present study, the effect of subgingival irrigation with gaseous ozone on G-AGP was evaluated, and the results showed that ozone 
provided a significant improvement in periodontal health by decreasing CAL and reducing $\mathrm{PI}$ and $\mathrm{GI}$ scores (Fig. 3).

CRP is considered to be an independent predictor of coronary heart disease. Some studies have suggested that CRP levels reflect particular low-grade infections related to chronic diseases such as CHD and periodontitis (22). A CRP level exceeding $10 \mathrm{mg} / \mathrm{L}$ is generally regarded as an indicative threshold of significant inflammatory disease (23). A positive association between CRP and periodontitis was also found in an analysis of the third National Health and Nutrition Examination Survey, suggesting a potential mechanism to link periodontitis with an increased risk for atherosclerotic complication (24). In addition, Ebersole et al. showed that CRP levels were significantly higher ( 9 vs. $2 \mathrm{mg} / \mathrm{L}$, respectively) in patients with moderate to severe CP (25).

Furthermore, periodontitis was shown to increase the levels of acute-phase reactants such as CRP due to the infectious characteristic of the disease (23). Based on this fact, it can be suggested that using antibacterial agents might decrease CRP levels in infectious diseases. Al Habashneh et al. showed that initial periodontal treatment with or without ozonised water irrigation decreased the PI, GI, BoP, CAL and high-sensitivity CRP levels in patients with CP (26). However, we could not observe the precise effects of treatment on the CRP levels in our study; instead, there was a great fluctuation.

\section{Conclusions}

Ozone is considered to be an effective antimicrobial agent, and based on the present findings, it can be suggested that ozone might be beneficial in treating diseases such as G-AGP. Within the limitations of this case report, it can be concluded that ozone application provided a significant improvement in clinical parameters, although the CRP levels were not affected. It is difficult to state that ozone application decreased the CRP levels in our patient with G-AGP, and hence, it is necessary to conduct long-term randomised clinical studies to observe the actual effect of ozone application on CRP levels.

Informed Consent: Written informed consent was obtained from the patient who participated in this study.

Peer-review: Externally peer-reviewed.

Author Contributions: Conception-H.B.Y.; Design-F.U.Y.; SupervisionF.T.; Materials - H.B.Y.; Data Collection and/or Processing - F.U.Y; Analysis and/or Interpretation-F.T.; Literature Review-F.U.Y; Writer-F.U.Y., H.B.Y.; Critical Review-F.U.Y., F.T.

Conflict of Interest: No conflict of interest was declared by the authors.

Financial disclosure: The authors declared that this study has received no financial support.

Acknowledgements: The authors deny any conflicts of interest related to this study.

\section{References}

1. Armitage, G.C., Development of a classification system for periodontal diseases and conditions. Ann Periodontol 1999; 4(1): 1-6. [Crossref]

2. Graetz, C., Dörfer CE, Kahl M, Kocher T, Fawzy El-Sayed K, Wiebe JF et al., Retention of questionable and hopeless teeth in compliant patients treated for aggressive periodontitis. J Clin Periodontol 2011; 38(8):707-14. [Crossref]

3. Silva-Senem MX, Heller D, Varela VM, Torres MC, Feres-Filho EJ, Colombo APV., Clinical and microbiological effects of systemic antimicrobials combined to an anti-infective mechanical debridement for the management of aggressive periodontitis: a 12-month randomized controlled trial. J Clin Periodontol 2013; 40(3): 242-51. [Crossref]

4. Demmer, R.T. and P.N. Papapanou, Epidemiologic patterns of chronic and aggressive periodontitis. Periodontol 2000 2010; 53(1): 28-44. [Crossref]

5. Deas, D.E. and B.L. Mealey, Response of chronic and aggressive periodontitis to treatment. Periodontol 2000 2010; 53(1): 15466. [Crossref]

6. Sherman, P., L. Hutchens Jr, and L. Jewson, The effectiveness of subgingival scaling and root planing II. Clinical responses related to residual calculus. J Periodontol 1990; 61(1): 9-15. [Crossref

7. Stambaugh, R., Dragoo M, Smith DM, Carasali L., The limits of subgingival scaling. Int J Periodontics Restorative Dent 1981; 1(5): 30-41. [Crossref

8. Bowen, J.A., Mellonig JT, Gray JL, Towle HT., Comparison of decalcified freeze-dried bone allograft and porous particulate hydroxyapatite in human periodontal osseous defects. J Periodontol 1989; 60(12): 647-54. [Crossref]

9. Claffey, N. and J. Egelberg, Clinical indicators of probing attachment loss following initial periodontal treatment in advanced periodontitis patients. J Clin Periodontol 1995; 22(9): 690-6. [Crossref]

10. Ramzy, M.I, Gomaa H. E., Mostafa M. I. and Zaki B., Management of aggressive periodontitis using ozonized water. Egypt Med JNR C 2005; 6(1): 229-45. [Crossref]

11. Kshitish, D. and V.K. Laxman, The use of ozonated water and $0.2 \%$ chlorhexidine in the treatment of periodontitis patients: A clinical and microbiologic study. Indian J Dent Res 2010; 21(3): 341-8. [Crossref]

12. Nogales, C.G., Ferrari PH, Kantorovich EO, Lage-Marques JL., Ozone therapy in medicine and dentistry. J Contemp Dent Pract, 2008. 9(4): 75-84. [Crossref]

13. Azarpazhooh, A. and H. Limeback, The application of ozone in dentistry: a systematic review of literature. J Dent 2008; 36(2): p. 104-116. [Crossref]

14. Saito, M., Ishimitsu T, Minami J, Ono H, Ohrui M, Matsuoka H., Relations of plasma high-sensitivity C-reactive protein to traditional cardiovascular risk factors. Atherosclerosis 2003; 167(1): 73-9. [Crossref]

15. Tüter, G., B. Kurtis, and M. Serdar, Evaluation of gingival crevicular fluid and serum levels of high-sensitivity C-reactive protein in chronic periodontitis patients with or without coronary artery disease. J Periodontol 2007; 78(12): 2319-24. [Crossref]

16. Silness J, Löe H. Periodontal disease in pregnancy II. Correlation between oral hygiene and periodontal condition. Acta Odontol Scand 1964; 22: 121-135. [Crossref]

17. Löe H, Silness J. Periodontal disease in pregnancy I. Prevalence and severity. Acta Odontol Scand 1963; 21: 533-551. [Crossref]

18. Ainamo J, Bay I. Problems and proposals for recording gingivitis and plaque. Int Dent J 1975; 25: 229-235. [Crossref]

19. Bollen, C.M. and M. Quirynen, Microbiological Response to Mechanical Treatment in Combination With Adjunctive Therapy. A Review of the Literature. J Periodontol 1996; 67(11): 1143-58. [Crossref]

20. Slots, J. and T.E. Rams, Antibiotics in periodontal therapy: advantages and disadvantages. J Clin Periodontol 1990; 17: 47993. [Crossref]

21. Seidler, V., Linetskiy I, Hubálková $H$, Stanková $H$, Smucler $R$, Mazánek J., Ozone and its usage in general medicine and dentistry. A review article. Prague Med Rep 2008; 109(1): 5-13. [Crossref] 
22. Lagrand, W.K., Visser CA, Hermens WT, Niessen HW, Verheugt FW, Wolbink GJ et al., C-reactive protein as a cardiovascular risk factor more than an epiphenomenon? Circulation 1999; 100(1): 96-102. [Crossref]

23. Noack, B., Genco RJ, Trevisan M, Grossi S, Zambon JJ, De Nardin $\mathrm{E}$, Periodontal infections contribute to elevated systemic Creactive protein level. J Periodontol 2001; 72(9): 1221-1227. [Crossref]

24. Slade, G.D., Offenbacher S, Beck JD, Heiss G, Pankow JS, Acutephase inflammatory response to periodontal disease in the US population. J Dental Res 2000; 79(1): 49-57. [Crossref
25. Ebersole, J., Machen RL, Steffen MJ, Willmann DE., Systemic acute-phase reactants, C-reactive protein and haptoglobin, in adult periodontitis. Clin Exp Immunol 1997; 107(2): 347-52. [Crossref]

26. Al Habashneh, R., W. Alsalman, and Y. Khader, Ozone as an adjunct to conventional nonsurgical therapy in chronic periodontitis: a randomized controlled clinical trial. J Periodontal Res 2015; 50(1): 37-43. [Crossref] 